Vol.45, Special n. : pp. 83-86, September 2002

ISSN 1516-8913 Printed in Brazil

\title{
Radiopharmaceuticals for Sentinel Node Detection
}

\author{
Malcolm Frier* \\ Queens Medical Centre; Nottingham University Hospital; Nottingham - UK
}

\begin{abstract}
Imaging of sentinel nodes is a valuable technique in the management of some types of cancer. Several different radiopharmaceuticals have been successfully employed in the technique, but there have been few systematic studies to examine the relationship between physicochemical properties of the radiopharmaceuticals used and in-vivo performance. The present study describes the preparation and characterisation of radiocolloids of similar chemical composition but differing in particle size distribution in an attempt to identify the role of variations in the single parameter of size.
\end{abstract}

Key words: Sentinel node, radiocolloid, particle size

\section{INTRODUCTION}

The property of interstitially-administered colloidal materials to be cleared via the lymph has been exploited for a number of years to investigate the functionality of the lymphatic system. It has been established since the 1950s that radioactivity migrates to cancerous lymph nodes after interstitial injection of colloidal gold (Au-198). However, the location of the radioactive colloidal particles within the cancerous nodes is limited to residual normal tissue, and not all cancercontaining nodes show colloidal uptake.

Interstitially-administered particulate materials migrate through the tissues and enter the lymph capillaries through junctions between interstitial cells, or by transport in vesicles through cells, by pinocytosis. They are then transported in lymph to nodes where they are phagocytosed by macrophages. Small particles (less than a few nanometres) are mostly exchanged through blood capillaries. Larger particles (a few tens of nanometres) are absorbed into lymph capillaries by the mechanisms described above. Large particles of a few hundreds of nanometres in size may remain trapped for long periods in the interstitial spaces.

Clinically, radioactive nanocolloids have been used for investigations of lymphatic drainage, and recently, more specifically for identification of the 'sentinel node' in investigations of metastatic spread of some cancers. Pijpers (1997) in his studies of breast cancer, used a technetium-99m colloidal albumin formulation (Nanocoll) with a particle size stated to be in the range $3-80 \mathrm{nM}$. Veronesi (1997) made use of a microaggregated albumin (AlbuRES), which has a considerably larger size range at about $250 \mathrm{nM}$, administered by a subdermal route. Cox (1998) has reported the use of a filtered sulphur colloid (Syncor) of unspecified particle size, injecting at sites on the periphery of the tumour. In a study involving 215 patients, Pagonelli (1998) examined the effects of 3 different colloidal tracers, antimony sulphide and

\footnotetext{
* Author for correspondence
} 
aggregated albumins ranging in size between $<50$ and $1000 \mathrm{nM}$, and two different administration sites, subdermal and peritumoral. Edriera (2001) has evaluated three different radiopharmaceuticals for sentinel lymph node identification in an animal model and has suggested that observed differences in behaviour between the formulations can be attributed to differences in particle size. However, to date no systematic study has been performed to identify the effects of changes in particle size alone.

There were two major objectives for the study:

- Preparation of colloids of the same composition but in different size ranges.

- Biodistribution and clearance studies in an animal model on the prepared materials to examine the influence of the single variable of size on behaviour

\section{MATERIALS AND METHODS}

Two nanocolloidal human albumin colloids and a sulphur colloid were used. Human Albumin nanocolloid (Nanocoll) (nhsa1) was obtained from Amersham Health, UK. Human Albumin nanocolloid (Sentiscint) (nhsa2) was obtained from Medi-Radiopharma Ltd, Hungary. Sulphur colloid (sc) was prepared from a kit manufactured by Medi-Physics Inc, USA.

Colloids were fractionated using Cyclopore Tracketched Membranes (Whatman) with pore sizes of 100,200 and $400 \mathrm{nM}$.

Gel chromatography was performed on a Sepharose 4B gel column (300 $\mathrm{mm} \times 15 \mathrm{~mm})$ eluted with physiological saline. Columns were developed at a flow rate of between 0.2 and $0.3 \mathrm{ml}$ per minute for 45 minutes followed by imaging and activity profile analysis on a gamma camera.

Particle sizing was performed by laser light scattering using a Malvern instruments PCS Nanosizer.

Biodistribution studies were performed in a rabbit model, by monitoring clearance of a subcutaneous injection from a site just below the sternum using a gamma camera. 30 dynamic frames of 60 seconds duration and a matrix size of $128 \times 128$ were acquired followed by 60 second static images at intervals of 30 minutes up to 5 hours.

\section{RESULTS AND DISCUSSION}

Gel chromatography of nhsa1 (Fig 1) showed the presence of a monodisperse system of small particle size. Subsequent analysis using the PCS nanosizer showed particle size to be in the range $20-30 \mathrm{nM}$. It was not possible further to fractionate this material. Gel chromatography of nhsa2 (Fig 2) also showed the presence of a monbodisperse system of small particle size. Subsequent analysis using the PCS nanosizer

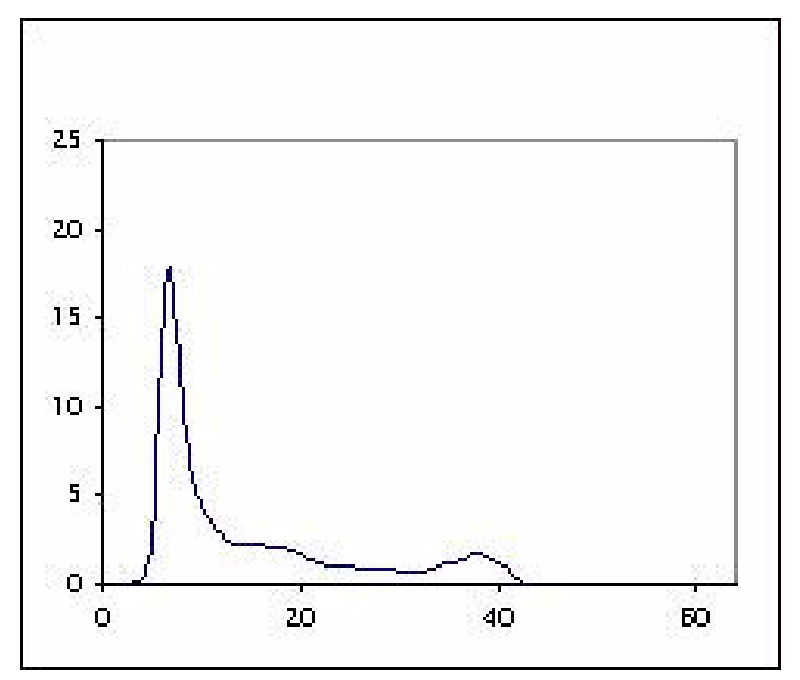

Figure 1 - Distance (pixel number)

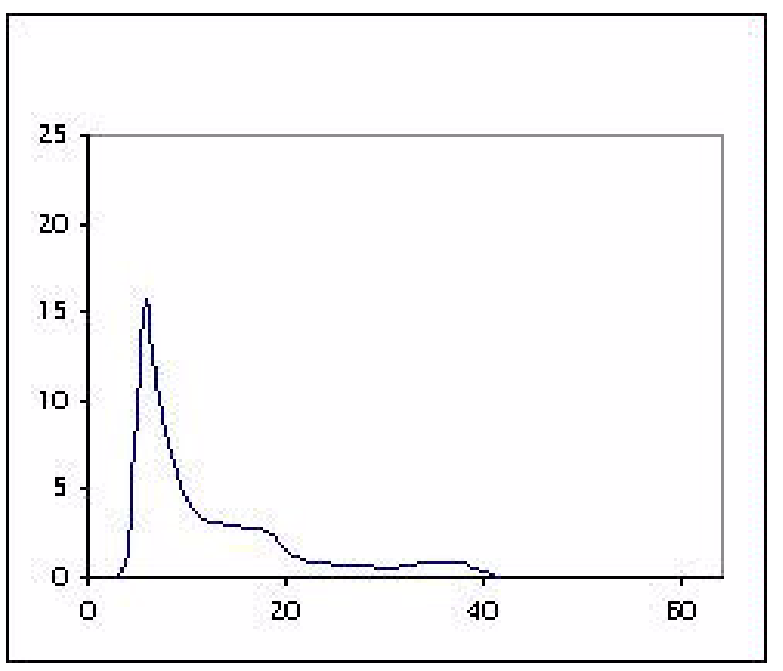

Figure 2 - Distance (pixel number) 
showed particle size to be in the range $30-50 \mathrm{nM}$. Again it was not possible further to fractionate this material.

Gel chromatography of sc (Fig 3) showed activity to be associated with two major size ranges. Subsequent PCS Nanosizer analysis showed radioactivity associated with two major fractions comprising particles $>400 \mathrm{~nm}$ in diameter, and $<100 \mathrm{~nm}$ in diameter mostly of $75 \mathrm{~nm}$. Membrane filtration allowed this material to be fractionated into two major fractions.

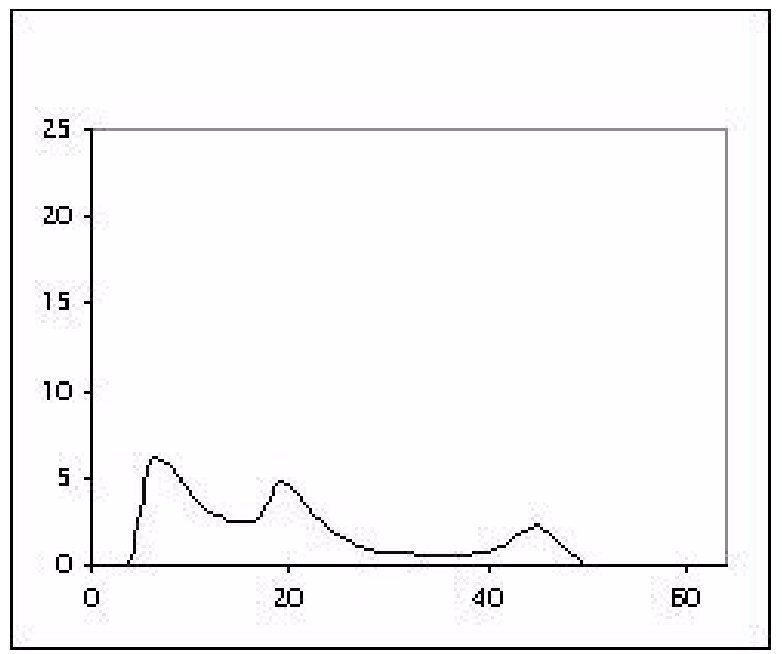

Figure 3 - Distance (pixel number)

Biodistribution studies were performed on the two nhsa products. Parasternal lymph nodes have been identified in each case but no significant differences in clearance rates have been demonstrated.

In sentinel node imaging and biopsy, the condition of the first lymph node draining a tumour can indicate the tumour state of the whole regional lymphatic basin, to the extent that a tumournegative sentinel node can virtually exclude lymphaticmetastatic spread.

Numerous radioactive colloidal preparations have been employed in nuclear medicine for imaging of the reticuloendothelial system and for lymphoscintigraphy. The essential difference between sentinel node detection and routine lymphoscintigraphy is that ideally only the first draining node should be identified and some authors have suggested a preference for a tracer of larger particle size such that radioactivity reaching the node will be totally extracted. However, if particle size is increased too far, clearance from the site of administration proceeds very slowly. Particle size may not be the only factor influencing the efficiency with which particles are engulfed by lymph nodes. An antimony sulphide colloid stabilized with PVP shows much slower clearance than one of the same particle size stabilized with gelatin (Frier 1981). The major problem is in identifying the contribution of each physicochemical parameter, since most comparative studies have involved more than one variable. It is also true that particle sizing data cannot easily be compared between different radiopharmaceuticals, since different methodologies produce results relating to particle diameter, surface area or volume. The above data suggest that the technique of fractionation of colloids is a viable method for the production of material differing only in the parameter of particle size. Fractionation requires that the starting material is polydisperse in nature, and gel filtration is suggested as a rapid and efficient way of identifying this property in radiocolloids. To date, difference in size ranges of the products investigated have not been sufficiently large to induce significant differences in clearance rate in the animal model used.

The choice of radiopharmaceutical for the detection of sentinel nodes may often be dictated by the commercial availability of suitable products, which will vary from country to country. These products vary considerably in chemical composition, in size distribution and in physicochemical characteristics. Gel filtration can be used to identify the polydisperse nature of radiocolloids. Membrane filtration is a practical method of producing discreet particle populations of chemically similar products. The sensitivity of the rabbit model to changes in particle size alone is as yet uncertain. There remains an important need for further understanding of these materials in order to standardise clinical procedures, and further systematic investigations are required in which the effect of each variable can be independently identified.

\section{ACKNOWLEDGEMENT}

The authors gratefully acknowledge the financial and material support of Nycomed Amersham in the continuing progress of this project. 


\section{RESUMO}

A imagem de nódulos sentinelas é uma técnica valiosa no acompanhamento de alguns tipos de câncer. Com esta finalidade diferentes radiofármacos têm sido empregados com sucesso, porém existem poucos estudos sistemáticos examinando a relação entre as propriedades físicoquímicas dos radiofármacos utilizados e sua performance in vivo. O presente estudo descreve a preparação e caracterização de radiocolóides com composição química similar diferindo sua distribuição no tamanho das partículas; na tentativa de identificar a importância de variações de tamanho como um único parâmetro.

\section{REFERENCES}

Bergqvist, L.; Strand, S. E. and Persson, B. R. R. (1983), Particle sizing and biokinetics of interstitial lymphoscintigraphic agents Seminars in Nuclear Medicine, 13, 9-19.

Cox, C. E.; Pendas, S.; Cox, J. M.; Joseph, E.; Shons, A. R.; Yeatman, T.; Ku, N. N.; Lyman, G. H.; Berman, C.; Haddad, F. and Reintgen, D. S. (1998), Guidelines for sentinel node biopsy and lymphatic mapping of patients with breast cancer Ann. Surg., 227, 645-651.
Edriera, M. M.; Colombo, L. L.; Perez, J. H.; Sajaroff, E. O. and Castiglia, S. G. (2001), In-vivo evaluation of three different Tc-99m labelled radiopharmaceuticals for sentinel node identification. Nucl. Med. Commun., 22499-504.

Frier, M. (1981), 'Phagocytosis' in Progress in Radiopharmacology. Ed. PH Cox, Elsevier, Holland. v. 2.

Paganelli, G.; De Ciccio, C.; Prisco, M.; Calza, P.; Luini, A.; Zucali, P. and Veronesi, U. (1998), Optimised sentinel node scintigraphy in breast cancer Q. J. Nucl. Med., 4249-53.

Pijpers, R.; Meijer, S.; Hoekstra, O. S.; Collet, G.J.; Comans, E. F.; Boom, R. P.; van Diest, P. J. and Teule, G. J. (1997), Impact of lymphoscintigraphy on sentinel node identification with technetium-99mcolloidal albumin in breast cancer. J. Nucl. Med., 38, 366-368.

Veronesi, U.; Paganelli, G.; Galimberti, V.; Viale, G.; Zurrida, S.; Bedoni, M.; Costa, A.; De Cicco, C.; Gerahty, J. G.; Luini, A; Saccini, V. and Veronesi, P. (1997), Sentinel-node biopsy to avoid axillary resection in breast cancer with clinically-negative lymph nodes Lancet, 349 : (9069), 1864-1867.

Received: June 28, 2002; Revised: July 05, 2002; Accepted: July 09, 2002. 